\title{
Bacterial outer membrane vesicles and the host-pathogen interaction
}

\author{
Meta J. Kuehn ${ }^{1}$ and Nicole C. Kesty \\ Department of Biochemistry, Duke University Medical Center, Durham, North Carolina 27710, USA
}

Extracellular secretion of products is the major mechanism by which Gram-negative pathogens communicate with and intoxicate host cells. Vesicles released from the envelope of growing bacteria serve as secretory vehicles for proteins and lipids of Gram-negative bacteria. Vesicle production occurs in infected tissues and is influenced by environmental factors. Vesicles play roles in establishing a colonization niche, carrying and transmitting virulence factors into host cells, and modulating host defense and response. Vesicle-mediated toxin delivery is a potent virulence mechanism exhibited by diverse Gram-negative pathogens. The biochemical and functional properties of pathogen-derived vesicles reveal their potential to critically impact disease.

In nearly every case, virulence factors of Gram-negative pathogens are secreted products that enhance the survival of the bacteria and/or damage the host. Secretion of virulence factors by Gram-negative pathogens is complicated by the fact that the bacterial envelope consists of two lipid bilayers, the inner and outer membrane, and the periplasm in between. Gram-negative pathogens have developed many strategies, some specific to pathogens, to enable active virulence factors to gain access to the extracellular environment, typically the tissues or bloodstream of the host organism (Henderson et al. 2004). The Type II and Type V secretion systems are two-step processes in which proteins are transported first through the inner membrane (IM) and then through the outer membrane (OM). For secretion via the Type I, Type III, and Type IV secretion systems, the material is transferred directly into the extracellular milieu or into another cell. The Type III system is specific for the transport of factors by pathogenic bacteria. All of these secretion systems secrete individual proteins or small complexes. This review examines secretion via OM vesicles, a distinct "Type VI" mechanism that enables bacteria to secrete a large, complex group of proteins and lipids into the extracellular milieu.

Both pathogenic and nonpathogenic species of Gram-

[Keywords: Secretion pathway; vesicles; blebs; outer membrane; virulence factors]

${ }^{1}$ Corresponding author.

E-MAIL meta.kuehn@duke.edu; FAX (919) 684-8885.

Article and publication are at http://www.genesdev.org/cgi/doi/10.1101/ gad.1299905 negative bacteria secrete vesicles (Mayrand and Grenier 1989; Kadurugamuwa and Beveridge 1997; Li et al. 1998; Beveridge 1999), including Escherichia coli (Hoekstra et al. 1976; Gankema et al. 1980), Shigella spp. (Kadurugamuwa and Beveridge 1999; Dutta et al. 2004), Neisseria spp. (Devoe and Gilchrist 1973; Dorward and Garon 1989), Bacteroides (including Porphyromonas) spp. (Grenier and Mayrand 1987; Mayrand and Holt 1988; Zhou et al. 1998), Pseudomonas aeruginosa (Kadurugamuwa and Beveridge 1995), Helicobacter pylori (Fiocca et al. 1999), Vibrio spp. (Chatterjee and Das 1967; Kondo et al. 1993), Salmonella spp. (Vesy et al. 2000; Wai et al. 2003), Brucella melitensis (Gamazo and Moriyon 1987), Campylobacter jejuni (Logan and Trust 1982; Blaser et al. 1983), Actinobacillus actinomycetemcomitans (Nowotny et al. 1982), Xenorhabdus nematophilus (Khandelwal and Banerjee-Bhatnagar 2003), and Borrelia burgdorferi (Shoberg and Thomas 1993). Studies of vesicles from diverse bacterial origins support a common function: Vesicles are a means by which bacteria interact with prokaryotic and eukaryotic cells in their environment.

Some of the best-characterized vesicles are those produced by pathogens. Biochemical analysis and functional characterization of pathogen-derived outer membrane vesicles demonstrate that this secretory pathway has been usurped by pathogens for the transport of active virulence factors to host cells (Table 1). Naturally produced OM vesicles from pathogenic bacteria contain adhesins, toxins, and immunomodulatory compounds, and they directly mediate bacterial binding and invasion, cause cytotoxicity, and modulate the host immune response. By participating in such diverse aspects of the host-pathogen interaction, OM vesicles are potent bacterial virulence factors.

\section{Formation of bacterial OM vesicles}

Naturally produced bacterial vesicles are discrete, closed OM blebs produced by growing cells, not products of cell lysis or cell death (Mug-Opstelten and Witholt 1978; Zhou et al. 1998; Yaganza et al. 2004; McBroom and Kuehn 2005). By electron microscopy, vesicles appear spherical with a bilayer membrane, electron-dense luminal content, and an average diameter of 50-250 nm, depending on the strain (Beveridge 1999). Vesicles are pelletable from a cell-free supernatant and, due to their lipid content, vesicles will fractionate into lighter density 
Table 1. Virulence factors associated with bacterial OM vesicles

\begin{tabular}{|c|c|c|}
\hline Species & Virulence factor & Reference \\
\hline Actinbacillus pleuropnemoniae & Proteases, ApxI & Negrete-Abascal et al. 2000 \\
\hline $\begin{array}{l}\text { Actinobacillus } \\
\text { actinomycetemcomitans }\end{array}$ & Leukotoxin & Nowotny et al. 1982; Kato et al. 2002 \\
\hline $\begin{array}{l}\text { Enterotoxigenic Escherichia coli } \\
\text { (ETEC) }\end{array}$ & LT & $\begin{array}{l}\text { Wensink et al. 1978; Gankema et al. 1980; } \\
\text { Wai et al. 1995; Horstman and Kuehn } 2000\end{array}$ \\
\hline $\begin{array}{l}\text { Shiga-toxin-producing E. coli (STEC) } \\
\text { and Enterohemorrhagic E. coli } \\
\text { (EHEC) }\end{array}$ & Shiga toxin & $\begin{array}{l}\text { Kolling and Matthews 1999; Yokoyama et al. } \\
2000\end{array}$ \\
\hline Enterohemorrhagic E. coli (EHEC) & ClyA & Wai et al. 2003 \\
\hline Helicobacter pylori & VacA & Fiocca et al. 1999; Keenan et al. 2000 \\
\hline Borrelia burgdorferi & OspA, OspD & Shoberg and Thomas 1993 \\
\hline Bacteroides fragilis & Haemagglutinin & Patrick et al. 1996 \\
\hline Pseudomonas aeruginosa & $\begin{array}{l}\text { Peptidoglycan hydrolase, phospholipase } \\
\text { C, hemolysin, alkaline phosphatase }\end{array}$ & $\begin{array}{l}\text { Kadurugamuwa and Beveridge 1995; Li et al. } \\
1998\end{array}$ \\
\hline Porphyromonas (Bacteroides) gingivalis & Arg-gingipain, Lys gingipain, proteases & $\begin{array}{l}\text { Grenier and Mayrand 1987; Kamaguchi et al. } \\
\text { 2003b; Duncan et al. } 2004\end{array}$ \\
\hline Salmonella typhi & ClyA & Wai et al. 2003 \\
\hline Shigella flexneri & IpaB, IpaC, IpaD & Kadurugamuwa and Beveridge 1998 \\
\hline Shigella dysenteriae & Shiga toxin & Dutta et al. 2004 \\
\hline Treponema denticola & Proteases, dentilisin & Rosen et al. 1995; Chi et al. 2003 \\
\hline Xenorhabdus nematophilus & $\begin{array}{l}\text { Chitinase, bacteriocin, adhesin, } \\
\text { pore-forming toxin }\end{array}$ & Khandelwal and Banerjee-Bhatnagar 2003 \\
\hline
\end{tabular}

fractions than solubly secreted proteins (Dorward et al. 1989; Horstman and Kuehn 2000; Allan et al. 2003). The OM of Gram-negative bacteria consists of proteins, such as porins, receptors, and pores, and an asymmetric distribution of lipids, with the outer leaflet composed primarily of lipopolysaccharide (LPS) and an inner leaflet containing phospholipids and lipoproteins. The periplasm contains the peptidoglycan (PG) layer, resident "housekeeping" proteins and enzymes, and resident and transient components of secretory pathways. Biochemical analysis of density gradient-purified OM vesicles demonstrated that native OM vesicles consist only of the protein and lipids of the OM and periplasm and do not contain IM and cytoplasmic components (McBroom and Kuehn 2005).

Enrichment and exclusion of vesicle membrane and soluble cargo as compared with their concentrations in whole bacteria point to vesicles as a specific secretory mechanism (Table 2). It is quite difficult to assess accurately the enrichment or exclusion of cargo. The localization of a protein in the whole cell influences its availability as vesicle cargo. For instance, a periplasmic protein that has affinity to the inner leaflet of the OM is more likely to appear "enriched" in vesicles when compared with the soluble periplasmic fraction of the whole cell, yet it may not be enriched when considering its concentration in the whole cell. Unfortunately, these affinities are often not known. Thus accurate enrichment/ exclusion values are best determined by comparing the quantities of a component in vesicles and in whole cells relative to the quantities of other components (Kesty et al. 2004).

Vesiculation is a ubiquitous process for Gram-negative bacteria grown in a variety of environments including liquid culture, solid culture, and in biofilms (Beveridge
1999|. In general, $0.2 \%-0.5 \%$ of OM and periplasmic proteins are packaged in vesicles from $E$. coli (Hoekstra et al. 1976; Mug-Opstelten and Witholt 1978; Kesty and Kuehn 2004), demonstrating that OM vesicle formation and release is an energy sink. In light of this, bacteria are unlikely to produce OM vesicles without function. In nonpathogenic bacteria, OM vesicles sometimes play a protective role: They contribute to bacterial survival by reducing levels of toxic compounds such as toluene and by aiding in the release of attacking phage (Loeb 1974; Loeb and Kilner 1978; Kobayashi et al. 2000).

Although OM vesicle production has been observed for more than 50 years, the machinery that allows vesicle secretion while maintaining bacterial viability remains elusive. Many theories exist on the mechanism of vesiculation based on biochemical and genetic data and are reviewed elsewhere (McBroom and Kuehn 2005). Based on budding events viewed by electron microscopy, outer membrane vesicles are thought to form when the OM bulges and pinches off, encapsulating soluble periplasmic cargo (Fig. 1; Chatterjee and Das 1967; Mayrand and Grenier 1989; Pettit and Judd 1992; Kadurugamuwa and Beveridge 1995; Li et al. 1998; Zhou et al. 1998). The maximum rate of vesicle production occurs during the end of log phase growth, as documented for $E$. coli, Vibrio cholerae, and $B$. melitensis, and vesicles are abundant at sites of cell division (Chatterjee and Das 1967; Hoekstra et al. 1976; Gamazo and Moriyon 1987).

As depicted in Figure 1, a reduction in the number of cross-links between the PG and the OM may govern sites of OM vesicle release (Hoekstra et al. 1976). The ties between the OM and PG are established during growth of the cell envelope, revealing how cell division could influence the quantity of vesicles produced (Chatterjee and Das 1967; Kadurugamuwa and Beveridge 1996; 
Table 2. Examples of enriched and excluded factors in bacterial OM vesicles

\begin{tabular}{|c|c|c|c|}
\hline Species & Excluded factor & Enriched factor & Reference \\
\hline $\begin{array}{l}\text { Actinobacillus } \\
\text { actinomycetemcomitans }\end{array}$ & Unidentified OM proteins & Leukotoxin, minor lipids & Kato et al. 2002 \\
\hline Bacteroides buccae & Unidentified OM proteins & & Williams and Holt 1985 \\
\hline Borrelia burgdorferi & Oms 28 porin & & Cluss et al. 2004 \\
\hline Brucella melitensis & Group 2 OM proteins & Phosphatidyl-choline & Gamazo and Moriyon 1987 \\
\hline Campylobacter jejuni & Unidentified OM proteins & $12 \mathrm{kDa}$ surface protein & Logan and Trust 1982 \\
\hline $\begin{array}{l}\text { E. coli } \mathrm{K}-12 \text { modified to } \\
\text { express ClyA }\end{array}$ & DsbA & ClyA & Wai et al. 2003 \\
\hline Enterotoxigenic E. coli & & LT, OmpW, OmpX & Horstman and Kuehn 2000 \\
\hline Porphyromonas gingivalis & & Unidentified OM proteins & Williams and Holt 1985 \\
\hline Pseudomonas aeruginosa & $\begin{array}{l}\text { A-band LPS, unidentified } \\
\text { OM proteins }\end{array}$ & $\begin{array}{l}\text { Aminopeptidase (in cystic fibrosis } \\
\text { sputum isolates), B-band LPS, } \\
\text { unidentified OM proteins }\end{array}$ & $\begin{array}{l}\text { Kadurugamuwa and Beveridge } \\
\text { 1995; S.J. Bauman and M.J. } \\
\text { Kuehn, unpubl. }\end{array}$ \\
\hline
\end{tabular}

Bernadac et al. 1998). The major lipoprotein Lpp contributes significantly to OM-PG linkages, and hypervesiculation results from a mutation in this gene (Bernadac et al. 1998; Cascales et al. 2002). However, the OM of the $1 p p$ mutant is also very fragile, and therefore the specific contribution to OM vesicle formation is unclear. Significant to the understanding of the mechanics of vesicle production, a deletion of $y f g L$ causes a dramatic decrease in vesicle production in an adherent-invasive strain of $E$. coli (AIEC) as well as an E. coli K12 strain (Rolhion et al. 2005). yfgL encodes a lipoprotein involved in the syntheses and/or degradation of PG (Eggert et al. 2001). Its role in vesicle budding is proposed to be the result of an increase in PG production, or the down-regulation of lytic transglycosylases that leads to a loss of turgor pressure on the OM (Rolhion et al. 2005).

In general, pathogenic bacteria produce more vesicles than their nonpathogenic counterparts (Lai et al. 1981; Wai et al. 1995). Quantitative analysis of the cell-free supernatants of mid-log phase cultures revealed that enterotoxigenic E. coli (ETEC) produce $\sim 10$-fold more vesicles than nonpathogenic E. coli (Horstman and Kuehn 2002). Similar patterns in vesicle production occur for leukotoxic and nonleukotoxic Actinobacillus actinomycetemcomitans: The pathogenic strains produce $>25$-fold more vesicles (Lai et al. 1981). A mutation in hns, a global regulatory factor that regulates many virulence factors, causes a threefold increase in E. coli vesicle production (Horstman and Kuehn 2002). These results are consistent with the hypothesis that pathogenic bacteria have usurped the basic process of vesicle production to disseminate virulence factors and improve survival in the host.

LPS structure impacts vesicle biogenesis directly and indirectly. P. aeruginosa strain PAO1, which expresses two types of $\mathrm{O}$-antigen side chain, produces vesicles enriched in the highly charged and longer "B-band" form (Kadurugamuwa and Beveridge 1995; Beveridge et al. 1997; Nguyen et al. 2003). B-band LPS enrichment in vesicles may occur due to budding from regions of the OM where adjacent B-band molecules are repulsed by charge, locally deforming the membrane (Kadurugamuwa and Beveridge 1996; Li et al. 1996). Consistent with this theory, PAO1 grown under oxygen stress conditions increases B-band LPS and demonstrates an increase in vesicle formation (Sabra et al. 2003). Salmonella and $P$. aeruginosa mutants missing the LPS O-antigen side chain also show increased vesicle formation (Smit et al. 1975; Meadow et al. 1978). The effects of core mutants on vesicle production are not yet resolved. Decreased OMP expression is associated with mutations in the core region of LPS (Ames et al. 1974; Smit et al. 1975; Schnaitman and Klena 1993); therefore, the vesiculation phenotypes seen in core LPS mutants (Meadow et al. 1978) could be indirect, the effect of altered outer membrane protein composition.

\section{Vesicle production during infection}

Vesicles from both intracellular and extracellular bacterial pathogens have been identified in diverse host tissues, revealing the ability of vesicles to access a variety of environments within the host. Because of their small size and the lack of known unique biological markers, OM vesicles are difficult to detect in biopsies and host specimens. Vesicle production and composition are influenced by environmental factors that pathogens experience inside the host.

Not surprisingly, vesicles are often observed near colonizing bacteria. Chronic Helicobacter pylori colonization of the stomach leads to peptic ulcers and, in some cases, cancer. Vesiculating $H$. pylori and vesicle binding to gastric cells have been detected in gastric biopsies and with tissue culture cells (Fiocca et al. 1999; Keenan et al. 2000). Vesicles containing vacuolating cytotoxin observed in $H$. pylori-colonized human gastric epithelium biopsies were similar in appearance and composition to H. pylori vesicles made in vitro (Fiocca et al. 1999; Keenan et al. 2000). Chlamydial OM vesicles were apparent in McCoy mouse fibroblast cells infected with either Chlamydia trachomatis or Chlamydia psittaci (Stirling and Richmond 1980). A B. burgdorferi isolate that causes Lyme disease was incubated with human skin for $24 \mathrm{~h}$ and was found to produce vesicles after invading in the dermis (Beermann et al. 2000).

Vesicles have also been detected in the fluids from 


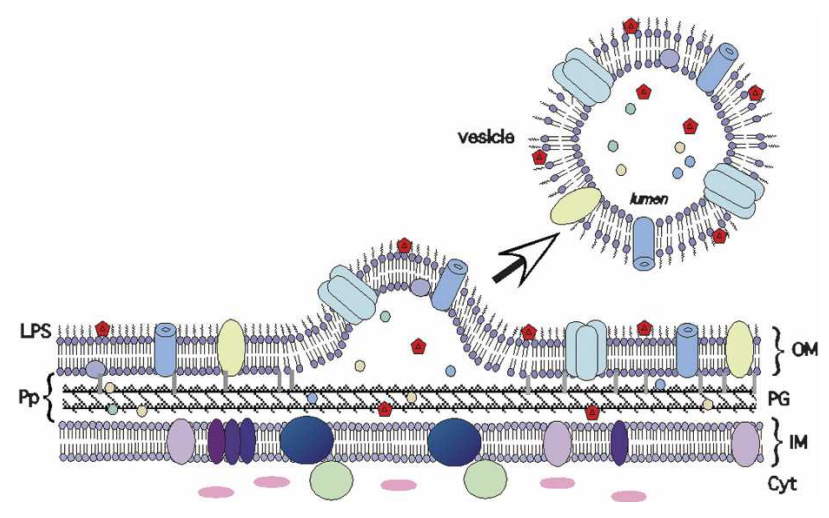

Figure 1. Model of vesicle biogenesis. OM vesicles are proteoliposomes consisting of OM phospholipids and LPS, a subset of OM proteins, and periplasmic (luminal) proteins. Proteins such as LT (red) that adhere to the external surface of the bacteria are associated with the external surface of vesicles. Proteins and lipids of the IM and cytosolic content are excluded from OM vesicles. Vesicles are likely to bud at sites where the links between the peptidoglycan and OM are infrequent, absent, or broken. (LPS) Lipopolysaccharide; (Pp) periplasm; (OM) outer membrane; (PG) peptidoglycan; (IM) inner membrane; (Cyt) cytosol.

infected hosts, demonstrating their ability to disseminate distant from the site of infection. Both vesiculating Neisseria meningitidis and freely diffused vesicles were detected in asymptomatic carriers and symptomatic patients, including in the cerebrospinal fluid from a patient with meningitis and blood from a patient who died from meningitis (Craven et al. 1980; Stephens et al. 1982; Brandtzaeg et al. 1992; Bjerre et al. 2000; Namork and Brandtzaeg 2002). Similarly, vesiculating Borrelia and free vesicles were detected in the urine and blood of $B$. burgdorferi-infected mice as well as in infected ticks (Dorward et al. 1991).

In some cases, structures similar to vesicles were detected but may not have been identified as vesicles. Bacterial vesicles are implicated in many aspects of periodontal disease including colonization, tooth destruction, inflammation, and disseminated sequelae /Grenier and Mayrand 1987; Mayrand and Grenier 1989; FivesTaylor et al. 2000). Structures that appear to be vesicles were discovered in dental plaque (Williams and Holt 1985; Mayrand and Grenier 1989). LPS and outer membrane protein-containing bacterial fragments were present in the serum of septic human patients (Brandtzaeg et al. 1992) and septic rats (Hellman et al. 2000a,b; Hellman and Warren 2001). E. coli grown in culture with serum shed outer membrane material with the same composition as the material found in the human serum (Hellman et al. 1997). Several factors identify this outer membrane material as vesicles: They are composed of LPS, they contain outer membrane proteins including OmpA and lipoproteins, they are $>0.1 \mu \mathrm{m}$ in size, and they are stable.

The intracellular pathogen Salmonella typhimurium secretes OM vesicles when growing intracellularly as well as into the supernatant of bacterial cultures (Garcia- del Portillo et al. 1997; Vesy et al. 2000; Bergman et al. 2005). When actively growing Salmonella is in intracellular compartments that have lost lysosomal membrane glycoproteins, intracellular LPS accumulates in similar compartments (Garcia-del Portillo et al. 1997).

LPS serotype switching, oxygen stress, the availability of iron, and the presence of antibiotics are all pertinent to pathogenic bacteria living inside the host, and these conditions impact vesicle production, toxicity, and composition. Altering expression of LPS O-antigens is a wellcharacterized defense strategy for pathogens to evade the host response (Pier 2000; Lerouge and Vanderleyden 2002). As described in the previous section, the presence and type of LPS O-antigen as well as the indirect effect of oxygen stress on the LPS structure may influence the physical ability of the membrane to bulge and initiate the formation of vesicles. Iron regulation is also a critical aspect of virulence. Bacteria such as $H$. pylori colonize intact mucosal as well as ulcerative host tissue; thus, they encounter different levels of iron in the host. Compared with typical iron-containing media, growth in iron-limiting media reduces VacA associated with $H$. pylori vesicles and increases the concentration of vesicleassociated proteases, although OM vesicle production levels are not affected (Keenan and Allardyce 2000). Antibiotics also influence vesicle production. Treatment of Shigella dysenteriae with mitomycin C, a known inducer of Shiga toxin, causes an increase in OM vesicle production, size, and toxicity (Dutta et al. 2004). Other antibiotics (fosfomycin, ciprofloxacin, and norfloxacin) do not significantly alter vesicle production or increase toxicity.

Gentamicin treatment of $P$. aeruginosa induces a threefold increase in the formation of vesicular structures that have distinct characteristics (Kadurugamuwa and Beveridge 1998). These structures contain gentamicin, fuse to host cells infected by pathogenic bacteria, and kill the intracellular bacteria by the cytosolic delivery of the antibiotic. Gentamicin-induced vesicles are larger and contain IM and cytosolic components as well as $\mathrm{OM}$ and periplasm. Thus, the composition of gentamicin-induced vesicles differs significantly from native OM vesicles, and they are assumed to be generated via a vastly different mechanism. This is supported by the fact that gentamicin-induced $P$. aeruginosa vesicles are not enriched in the B-band LPS characteristic of native vesicles. Nevertheless, these studies reveal both the impact of the antibiotics on the number of released bacterial membrane structures, as well as the biochemical fusogenic capacity of the surface of vesicles that reflects on the ability of native OM vesicles to interact with neighboring cells.

\section{Interbacterial activities}

Some bacteria use vesicles as an offensive tactic to gain a growth advantage over other bacteria. Protease- and toxin-containing vesicles from E. coli, Shigella, Actinobacillus, Pseudomonas, and Borrelia can interact with bacteria possibly via a fusion or adherence mechanism 
(Gankema et al. 1980; Shoberg and Thomas 1993; Kadurugamuwa and Beveridge 1998, 1999; Saunders et al. 1999; Kato et al. 2002). Vesicle fusion delivers proteins, such as the autolysin murein hydrolase, that can lyse other ("non-self") Gram-positive and Gram-negative bacteria (Kadurugamuwa et al. 1998; Li et al. 1998). "Self"-fusion events between vesicles and the strain of bacteria from which they derive are not lethal due to the regulated activity of such proteins in the periplasm. Gentamicin-induced $P$. aeruginosa vesicles are also bacteriolytic (Kadurugamuwa and Beveridge 1996; Allan and Beveridge 2003). These studies demonstrate that vesicles could aid in securing a niche in a competitive bacterial environment, such as during the colonization of a host.

Vesicles also are a means to transfer beneficial material between bacteria and contribute to genetic diversity and bacterial survival. Native $P$. aeruginosa vesicles are able to transfer antibiotic-resistance enzymes to other bacteria (Ciofu et al. 2000), enhancing survival of neighboring bacteria. Vesicles carry luminal DNA as well as DNA on their surface. In several cases, vesicles were reported to package chromosomal, plasmid, and phage DNA, presumably from the periplasm (Dorward et al. 1989; Kolling and Matthews 1999; Yaron et al. 2000). The source and destination of this DNA may depend on the bacterial species or strain. Renelli et al. (2004) demonstrated that DNA from the environmental media is encapsulated by $P$. aeruginosa vesicles. In some instances, vesicle-associated, nuclease-resistant DNA is capable of transforming neighboring bacteria (Dorward et al. 1989; Kolling and Matthews 1999; Yaron et al. 2000), however, this is apparently not the case for all vesicle-associated DNA (Renelli et al. 2004). For A. actinomycetemcomitans, DNA is also associated with vesicles, but it is localized to the exterior surface, where it binds secreted leukotoxin (Ohta et al. 1991, 1993).

In addition to facilitating interbacterial material transfer, vesicles can mediate coaggregation of bacteria, enabling biofilm formation and colonization (Grenier and Mayrand 1987; Whitchurch et al. 2002). In particular, numerous oral bacteria produce vesicles that induce microbial aggregation, interact with host cells, and display toxic activities (Williams and Holt 1985; Mayrand and Grenier 1989). Porphyromonas gingivalis, one of the bacteria responsible for periodontal disease, produces vesicles with the potential to induce autoaggregation and coaggregation with other bacteria. In vitro, P. gingivalis vesicles coaggregated various oral microorganisms including Eubacterium saburreum with Capnocytophaga ochracea; Staphylococcus aureus with various Streptococcus spp.; Actinomyces spp. and myceliumtype Candida albicans; and P. gingivalis with Prevotella intermedia (Grenier and Mayrand 1987; Kamaguchi et al. 2003a,b). The proteolytic and adhesive activity of $P$. gingivalis vesicles is due to the presence of gingipains (Grenier and Mayrand 1987; Patrick et al. 1996; Kamaguchi et al. 2003b). Another oral bacterial species, A. actinomycetemcomitans, also produces vesicles with proteolytic and coaggregative abilities (Nowotny et al. 1982; Meyer and Fives-Taylor 1994; Negrete-Abascal et al.
2000). Hence, vesicles could have an impact on both the establishment and the longevity of a bacterial infection. In light of their bacteriocidal, aggregative, and/or transforming activities, vesicles produced by colonizing pathogens are likely to have a complex and as yet unexplored impact on the commensal or coinfecting bacterial population.

\section{Adherence and entry into host cells and tissues}

Membrane vesicles are natural vehicles, or bacterial "bombs," for directed intercellular transport of particular bacterial virulence factors into host cells and tissues. Toxins, protease, adhesins, and other virulence factors in addition to LPS (endotoxin) have been coisolated with native vesicles from the culture supernatants of many pathogens (Table 1). Vesicle surface factors can mediate adhesion to eukaryotic cells as well as subsequent internalization of vesicle material. The ability of native bacterial OM vesicles to fuse with host cells and deliver content directly into the cytosol has been theorized based on their ability to fuse with bacterial membranes; however, currently this mechanism is not substantiated. Based on their adhesive and proteolytic properties and their small size, OM vesicles can interact with specific host cells deep in tissues that are not readily accessible by the infecting bacteria.

Gram-negative pathogens often express surface adhesins, so it is not surprising that vesicles, which consist of a subset of OM proteins, also are adhesive. The method of vesicle binding and internalization generally reflects that of the bacterial cells. However, in many cases bacterial adhesins are fimbrial, and thus far no fimbriae (pili) have been detected to originate from purified vesicles. Unless there is a specific exclusion machinery, there is no reason why the OM protein-anchored Type I or P pili (Stathopoulos et al. 2000) would not be present in vesicles. In contrast, it is unlikely that Type IV pili are associated with vesicles, since these originate from an IM protein complex (Stathopoulos et al. 2000).

Surface factors of pathogens are genetically regulated during infection in order for the bacteria to adhere to host cells, enter host cells, and evade the immune response. The composition of vesicles from pathogens should reflect the state of the bacterial OM, and therefore depend on the site of culturing of the bacteria. Vesicles were purified from clinical isolates of $P$. aeruginosa from patients with cystic fibrosis (CF) and their composition was compared with vesicles from a laboratory P. aeruginosa strain (S.J. Bauman and M.J. Kuehn, unpubl.). In addition to the lack of LPS with O-antigen, typical of $P$. aeruginosa clinical isolates (Pier 2000), the vesicles are enriched for a surface-localized aminopeptidase and bind better to lung epithelial cells when compared with the laboratory strain-derived vesicles.

Toxins associated with the external vesicle surface act as adhesins for some vesicles, and the interaction between the toxin and the eukaryotic cell receptor governs subsequent uptake of the vesicle into the host cell. For instance, external, LPS-bound heat labile enterotoxin 
(LT) is the adhesin responsible for ETEC vesicle interactions with host cells (Horstman and Kuehn 2000; Kesty et al. 2004). The $\mathrm{LT}_{\mathrm{B}}$ subunit responsible for the eukaryotic cell interactions is also responsible for binding LPS; however, a non- $\mathrm{G}_{\mathrm{M1}}$-binding $\mathrm{LT}_{\mathrm{B}}$ mutant also bound LPS, indicating that the Kdo- and $\mathrm{G}_{\mathrm{M1}}$-binding areas of $\mathrm{LT}_{\mathrm{B}}$ are distinct (Horstman and Kuehn 2002). These data are consistent with LT acting as a vesicle adhesin, a bridge between the LPS of the vesicle and $G_{M 1}$ of the host cell.

Association and internalization of ETEC vesicles into host cells depend specifically on the interactions between the LT and its receptor, $\mathrm{G}_{M 1}$; thus, LT acts as a host cell adhesin for vesicles. Because $G_{M 1}$ binding leads to lipid raft-mediated endocytosis, ETEC vesicles are internalized by this nondegradative, cholesterol-dependent pathway (Kesty et al. 2004). Multiple components of ETEC vesicles, including luminal components and structures that morphologically resemble bacterial vesicles, are found inside epithelial cells incubated with the vesicles, demonstrating that intact ETEC vesicles are taken up by intestinal cells (Kesty and Kuehn 2004).

Vacuolating toxin (VacA) is externally associated with H. pylori vesicles (Sommi et al. 1998; Fiocca et al. 1999; Heczko et al. 2000; Keenan et al. 2000), and, like soluble VacA, endocytosed vesicles accumulate in vacuoles. This suggests that vesicle-bound VacA directs the binding and internalization of $H$. pylori vesicles similarly to the LT-mediated binding and entry of ETEC vesicles.

In contrast, although leukotoxin is associated with the surface of $A$. actinomycetemcomitans OM vesicles, the toxin is not responsible for the adherence of the vesicles with HL60 human myeloid leukemia cells (Demuth et al. 2003). After a brief, 2-min incubation, A. actinomycetemcomitans OM vesicle antigens are found around the periphery of the cells. Based on the fast kinetics, the lack of intracellular label, and the insensitivity to cytochalasin D, the appearance of vesicle antigens in HL60 cell membranes is probably the result of adherent vesicles rather than their endocytosis.

Antibiotic-containing vesicles from Shigella flexneri adhere to and enter cultured Henle cells within $1 \mathrm{~h}$, causing dramatic killing of intracellular Shigella by the delivery of their antibacterial soluble vesicle content (Kadurugamuwa and Beveridge 1998). Uptake of these vesicles by human intestinal cells is predicted to be catalyzed by the outer membrane invasins present in the vesicles, IpaB, C, and D.

Binding of vesicles to host cells can also influence binding of bacteria to those cells. B. burgdorferi, the spirochete responsible for the autoimmune Lymes disease, produces vesicles that bind human umbilical vein epithelial (HUVE), dendritic, and endothelial cells (Shoberg and Thomas 1993; Saunders et al. 1999). This binding competes for bacterial cell receptors and may be due to outer membrane proteins OspA and OspB (Shoberg and Thomas 1993). Rather than inhibiting bacterial binding, Actinobacillus vesicles enhance the adherence of Actinobacillus to oral KB epithelial cells (Meyer and FivesTaylor 1994).
The ability of some bacteria to invade human intestinal epithelial cells is also linked to OM vesicles. A noninvasive AIEC bacterial mutant was discovered to have a defect in OM vesicle formation (Rolhion et al. 2005). It is proposed that the AIEC OM vesicles carry effectors into the host cell that lead to uptake of bacteria. The AIEC vesicles can work in trans, for example, OM vesicles from the wild-type AIEC strain, but not a K-12 strain, enable entry of the noninvasive AIEC bacterial mutant.

$\mathrm{OM}$ vesicles have been proposed to act as long-range virulence factors that can protect luminal cargo from extracellular host proteases and penetrate into tissues more readily than the larger bacteria. In support of this theory, purified Treponema denticola vesicles harbor dentilisin, a protease that allows $T$. denticola to penetrate the epithelial barrier, and the vesicles also disrupt the tight junctions of a Hep-2 epithelial cell monolayer (Chi et al. 2003). Proteins inside the vesicles are insensitive to protease treatment (Kolling and Matthews 1999; Horstman and Kuehn 2000).

Similar to bacterial-host cell interactions, vesiclehost cell interactions can be altered by manipulating the expression of outer membrane proteins in bacteria. The Yersinia entercolitica outer membrane protein Ail confers an invasive phenotype to a laboratory E. coli strain (Miller and Falkow 1988). The Ail adhesin/invasin expressed in laboratory E. coli is present in purified OM and OM vesicles produced by these strains. The Ail-containing vesicles display 10 -fold higher association with host cells than vesicles from a laboratory strain not expressing Ail (Kesty and Kuehn 2004). The manipulation of vesicle adherence and entry is intriguing considering the prospective use of engineered vaccine strains for antigen delivery.

\section{Toxin transporters}

Active toxins are associated with several pathogen-derived vesicles (Table 1), and some of the toxins appear to be enriched in vesicles (Table 2). In some cases, vesicleassociated toxins are more active than the toxins alone, and some toxins are associated with the exterior surface of vesicles. The host cell response to the delivery of vesicle-associated toxin is likely to be quite different from that to the delivery of soluble toxin if the uptake of vesicle-associated toxin is coincident with the uptake with vesicles. This is anticipated for OM vesicles such as those produced by ETEC: Vesicle-associated LT is not only toxic, it also causes the internalization of other bacterial components, including membrane proteins, periplasmic proteins, and endotoxin, into the host cell (Fig. 2; Kesty et al. 2004).

Vesicles play a major role in the export and activity of some bacterial toxins. More than $95 \%$ of secreted LT activity is associated with vesicles (Horstman and Kuehn 2002). After secretion through the OM by the Type II general secretory pathway (Horstman and Kuehn 2002; Tauschek et al. 2002), LT becomes associated with LPS on the extracellular surface of the OM (Horstman and Kuehn 2002). Thus, when OM vesicles form, these 


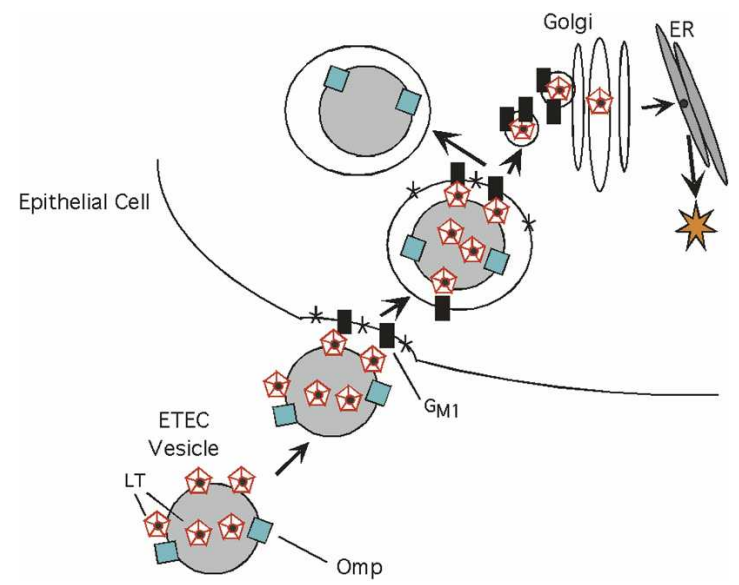

Figure 2. Model of toxin transmission to epithelial cells via ETEC vesicles. ETEC vesicles carry toxin (LT) on their surfaces and in their lumens. Surface-associated LT binds $\mathrm{G}_{\mathrm{M} 1}$ ganglioside (black rectangles), which is located in cholesterol-rich microdomains (caveolae) of host cell plasma membranes (asterisks). Vesicles are internalized into a nonacidified compartment, the toxin enters the Golgi, and the $\mathrm{LT}_{\mathrm{A}}$ subunit of the toxin (black circle) is trafficked by retrograde transport via the endoplasmic reticulum (ER) to the cytosol, where it is active. Accumulation of the bacterial vesicles inside the cells accompanies LT-mediated vesicle entry.

contain luminal LT originating from the periplasm, as well as external, LPS-associated LT (Fig. 2). The minimal structure recognized by LT is the Kdo (3-deoxy-Dmanno-octulosonic acid) portion of LPS, and intriguingly, phosphorylation of Kdo inhibits binding by LT as well as its close homolog, cholera toxin (CT) (Horstman et al. 2004). The difference in soluble secretion of CT by $V$. cholerae, compared with the vesicle-associated secretion of LT by ETEC, is therefore explained by the expression of phosphorylated Kdo on the LPS of $V$. cholerae.

The secreted form of cytolysin A (ClyA) is found in vesicles released from $E$. coli, and an in-depth study of ClyA secretion via vesicles revealed a unique property of OM vesicles (Wai et al. 2003). ClyA in the periplasm is oxidized, with cysteines participating in disulfide bonds that render it unable to oligomerize and become inactive. The reduction of the cysteines is critical for the conversion of ClyA into active oligomers, and interestingly, the vesicle lumen has a different redox state than the periplasm due to uncoupling of periplasmic and IM factors of the Dsb pathway. As a result of the reducing environment of the vesicle, possibly in addition to an increase in local concentration, ClyA forms active oligomeric pore structures in the vesicles. Large polymeric ClyA structures are clearly visible by electron microscopy on the surface of $E$. coli vesicles. Vesicle-associated ClyA was more toxic than a similar concentration of purified periplasmic toxin, presumably due to its proper folding into an active structure.

Leukotoxin, which kills human polymorphonuclear leukocytes and monocytes, is enriched in A. actinomycetemcomitans vesicles; the vesicles fuse to eukaryotic cell membranes and can cause cell lysis; and vesicleassociated leukotoxin is more potent than leukotoxin associated with OM (Kato et al. 2002). Unlike LT for ETEC vesicles, leukotoxin binds nucleic acid on the OM surface (Ohta et al. 1991, 1993; Demuth et al. 2003). A. actinomycetemcomitans vesicles also have calcium-releasing and bone-resorption activities associated with tooth loss (Nowotny et al. 1982; Meyer and Fives-Taylor 1994; Negrete-Abascal et al. 2000).

Complexes that include endotoxin and bacterial lipoproteins, consistent with the characteristics of vesicles, are released by $S$. flexneri and are cytotoxic to macrophages, demonstrating a role for vesicles in key apoptotic events during dysentery (Aliprantis et al. 2001). Enterohemorrhagic E. coli O157:H7 and S. dysenteriae produce vesicles that contain active Shiga toxin (Kolling and Matthews 1999; Yokoyama et al. 2000; Dutta et al. 2004). Vesicle-associated Shiga toxin appears partially protease sensitive and partially protease protected, suggesting both vesicle surface and luminal localization.

OM vesicles produced by enteric insect pathogens have also been analyzed. $X$. nematophilus OM vesicles are insecticidal for neonatal larvae and are more potent than purified OM proteins (Khandelwal and BanerjeeBhatnagar 2003). These vesicles harbor chitinase activity.

Vacuolating toxin, VacA, has been detected closely associated with the membrane of $H$. pylori vesicles (Keenan et al. 2000). Vesicular VacA is stable in the eukaryotic cell, and its toxicity, which is urease dependent, can be induced days following internalization (Sommi et al. 1998). Since urease is secreted by $H$. pylori into the gastric mucosa but vesicles do not carry urease (Keenan et al. 2000), this may be part of an elaborately regulated virulence mechanism that is not yet fully understood.

\section{Modulation of host response}

In addition to specific virulence factors, vesicles contain compounds that are recognized by eukaryotic cells in the innate and acquired immune response pathways. Considering that properties of the OM change during a bacterial infection (such as the $\mathrm{O}$ antigen of LPS), the impact of vesicles on the modulation of the immune system will also vary during the course of infection. B-cells activate upon coincubation with vesicles from $B$. burgdorferi (Whitmire and Garon 1993). N. meningitidis vesicles were highly immunogenic when administered intranasally into mice, eliciting a mucosal and systemic bactericidal antibody response (Saunders et al. 1999). This is not surprising since OM vesicles contain a natural adjuvant (endotoxin) and surface-localized bacterial antigens. Mice infected with $S$. typhimurium generate $\mathrm{CD}^{+} \mathrm{T}$ cells that recognize antigens in Salmonella OM vesicles (Ernst et al. 2001). Intriguingly, Salmonella OM vesicles carry antigens in addition to LPS that are also regulated by $\mathrm{PhoP} / \mathrm{Q}$, suggesting that the Salmonella coordinately reduces recognition for both innate and adaptive immune systems (Bergman et al. 2005).

An overstimulated inflammatory response to a pathogen is destructive for the host. LPS, lipoprotein, and 
OMPs present in vesicles are all biologically active molecules that can activate immune cells via Toll-like receptors (TLRs) and induce leucocyte migration (Galdiero et al. 1999; Akira et al. 2001). Oral bacteria often cause an inflammatory response, and vesicles from oral bacteria are active in modulating host responses (Mayrand and Holt 1988; Duncan et al. 2004). IL-8 production from gastric epithelial cells is stimulated by $H$. pylori vesicles, and stimulation is independent of the VacA toxin (Ismail et al. 2003). Therefore, bacterial vesicles that do not carry exotoxins can nevertheless cause damage due to the host inflammatory response.

Vesicles may enable bacteria to escape immune detection during colonization. Neisseria vesicles have been proposed to act as decoys to the immune system, binding and removing cell-targeted bactericidal factors in serum (Pettit and Judd 1992). The gingipain proteases on P. gingivalis vesicles cause CD14 degradation on O937 human macrophages that could lead to disarming the responsiveness of the immune system in periodontal disease (Duncan et al. 2004) P. gingivalis vesicles also induce membrane expression of E-selectin and ICAM-1 on vascular endothelial cells, whereas they inhibit synthesis of interferon $\gamma$ MHC class II synthesis (Srisatjaluk et al. 1999, 2002).

As a result of severe periodontitis, dental inflammation, or dental treatments, oral bacteria may disseminate through the bloodstream. Here, vesicles also are predicted to play important roles. $P$. gingivalis vesicles induce murine macrophage foam cell formation, which is thought to be causal to coronary thrombosis by loosening plaques in the arterial wall (Qi et al. 2003). P. gingivalis vesicles also are potent activators and aggregative factors for murine platelets, whereas vesicles from other oral bacteria do not show these activities (Sharma et al. 2000).

\section{Summary and future directions}

As a bacterial secretion system, vesicles are unique. Vesicles enable the extracellular dispersal of specific proteins as part of complexes of proteins and lipids that can act synergistically to activate toxic and immune pathways in the host. By virtue of their small size, adhesive properties, endotoxic component, and ability to carry and deliver toxic components into host cells, outer membrane vesicles are likely to play a significant role in disseminating virulence factors for Gram-negative pathogens. Vesicles can also help carve out a niche in the environment by modulating interactions between neighboring bacteria and between bacteria and the immune system.

The activation of the ClyA toxin within secreted $E$. coli vesicles reveals an unprecedented level of sophistication for OM vesicles to participate in the generation of a toxic virulence factor. In the case of ETEC vesicles, the use of the toxin as a vesicle adhesin complicates the scenario of toxin delivery into host cells by the concomitant introduction of stimulatory bacterial compounds inside host cells that are not normally phagocytic. Conse- quently, whereas it will not be surprising to find other examples of vesicle involved in mediating virulence factor activity, the molecular details by which this occurs remain unpredictable.

In the future, studies of vesicles will likely turn toward the gene products involved in their formation and the basis by which virulence factors, membrane, and periplasmic cargo are included or excluded. In addition, it will be important to understand which host factors influence vesicle release, and how the environmental conditions are translated into the mechanics of OM vesicle production. The data thus far guarantee many more interesting and surprising discoveries regarding the impact and significance of bacterial OM vesicles in the host-pathogen interaction.

\section{Acknowledgments}

M.J.K. is supported by the Burroughs Wellcome Investigator in Pathogenesis of Infectious Disease Award and grants from the NIAID/NIH.

\section{References}

Akira, S., Takeda, K., and Kaisho, T. 2001. Toll-like receptors: Critical proteins linking innate and acquired immunity. Nat. Immunol. 2: 675-680.

Aliprantis, A.O., Weiss, D.S., Radolf, J.D., and Zychlinsky, A. 2001. Release of Toll-like receptor-2-activating bacterial lipoproteins in Shigella flexneri culture supernatants. Infect. Immun. 69: 6248-6255.

Allan, N.D. and Beveridge, T.J. 2003. Gentamicin delivery to Burkholderia cepacia group IIIa strains via membrane vesicles from Pseudomonas aeruginosa PAO1. Antimicrob. Agents Chemother. 47: 2962-2965.

Allan, N.D., Kooi, C., Sokol, P.A., and Beveridge, T.J. 2003. Putative virulence factors are released in association with membrane vesicles from Burkholderia cepacia. Can. J. Microbiol. 49: 613-624.

Ames, G.F., Spudich, E.N., and Nikaido, H. 1974. Protein composition of the outer membrane of Salmonella typhimurium: Effect of lipopolysaccharide mutations. I. Bacteriol. 117: 406-416.

Beermann, C., Wunderli-Allenspach, H., Groscurth, P., and Filgueira, L. 2000. Lipoproteins from Borrelia burgdorferi applied in liposomes and presented by dendritic cells induce CD8 ${ }^{+}$T-lymphocytes in vitro. Cell Immunol. 201: 124-131.

Bergman, M.A., Cummings, L.A., Barrett, S.L., Smith, K.D., Lara, J.C., Aderem, A., and Cookson, B.T. 2005. CD4 ${ }^{+}$T cells and toll-like receptors recognize Salmonella antigens expressed in bacterial surface organelles. Infect. Immun. 73: $1350-1356$.

Bernadac, A., Gavioli, M., Lazzaroni, J.C., Raina, S., and Lloubes, R. 1998. Escherichia coli tol-pal mutants form outer membrane vesicles. J. Bacteriol. 180: 4872-4878.

Beveridge, T.J. 1999. Structures of Gram-negative cell walls and their derived membrane vesicles. J. Bacteriol. 181: 4725-4733.

Beveridge, T.J., Makin, S.A., Kadurugamuwa, J.L., and Li, Z. 1997. Interactions between biofilms and the environment. FEMS Microbiol. Rev. 20: 291-303.

Bjerre, A., Brusletto, B., Rosenqvist, E., Namork, E., Kierulf, P., Ovstebo, R., Joo, G.B., and Brandtzaeg, P. 2000. Cellular activating properties and morphology of membrane-bound and purified meningococcal lipopolysaccharide. I. Endotoxin Res. 6: 437-445. 
Blaser, M.J., Hopkins, J.A., Berka, R.M., Vasil, M.L., and Wang, W.L. 1983. Identification and characterization of Campylobacter jejuni outer membrane proteins. Infect. Immun. 42: $276-284$.

Brandtzaeg, P., Bryn, K., Kierulf, P., Ovstebo, R., Namork, E., Aase, B., and Jantzen, E. 1992. Meningococcal endotoxin in lethal septic shock plasma studied by gas chromatography, mass-spectrometry, ultracentrifugation, and electron microscopy. J. Clin. Invest. 89: 816-823.

Cascales, E., Bernadac, A., Gavioli, M., Lazzaroni, J.C., and Lloubes, R. 2002. Pal lipoprotein of Escherichia coli plays a major role in outer membrane integrity. I. Bacteriol. 184: 754-759.

Chatterjee, S.N. and Das, J. 1967. Electron microscopic observations on the excretion of cell-wall material by Vibrio cholerae. J. Gen. Microbiol. 49: 1-11.

Chi, B., Qi, M., and Kuramitsu, H.K. 2003. Role of dentilisin in Treponema denticola epithelial cell layer penetration. Res. Microbiol. 154: 637-643.

Ciofu, O., Beveridge, T.J., Kadurugamuwa, J., Walther-Rasmussen, J., and Hoiby, N. 2000. Chromosomal $\beta$-lactamase is packaged into membrane vesicles and secreted from Pseudomonas aeruginosa. J. Antimicrob. Chemother. 45: 9-13.

Cluss, R.G., Silverman, D.A., and Stafford, T.R. 2004. Extracellular secretion of the Borrelia burgdorferi Oms28 porin and Bgp, a glycosaminoglycan binding protein. Infect. Immun. 72: 6279-6286.

Craven, D.E., Peppler, M.S., Frasch, C.E., Mocca, L.F., McGrath, P.P., and Washington, G. 1980. Adherence of isolates of Neisseria meningitidis from patients and carriers to human buccal epithelial cells. J. Infect. Dis. 142: 556-568.

Demuth, D.R., James, D., Kowashi, Y., and Kato, S. 2003. Interaction of Actinobacillus actinomycetemcomitans outer membrane vesicles with HL60 cells does not require leukotoxin. Cell Microbiol. 5: 111-121.

Devoe, I.W. and Gilchrist, J.E. 1973. Release of endotoxin in the form of cell wall blebs during in vitro growth of Neisseria meningitidis. J. Exp. Med. 138: 1156-1167.

Dorward, D.W. and Garon, C.F. 1989. DNA-binding proteins in cells and membrane blebs of Neisseria gonorrhoeae. J. Bacteriol. 171: 4196-4201.

Dorward, D.W., Garon, C.F., and Judd, R.C. 1989. Export and intercellular transfer of DNA via membrane blebs of Neisseria gonorrhoeae. J. Bacteriol. 171: 2499-2505.

Dorward, D.W., Schwan, T.G., and Garon, C.F. 1991. Immune capture and detection of Borrelia burgdorferi antigens in urine, blood, or tissues from infected ticks, mice, dogs, and humans. J. Clin. Microbiol. 29: 1162-1170.

Duncan, L., Yoshioka, M., Chandad, F., and Grenier, D. 2004. Loss of lipopolysaccharide receptor CD14 from the surface of human macrophage-like cells mediated by Porphyromonas gingivalis outer membrane vesicles. Microb. Pathog. 36: 319-325.

Dutta, S., Iida, K., Takade, A., Meno, Y., Nair, G.B., and Yoshida, S. 2004. Release of Shiga toxin by membrane vesicles in Shigella dysenteriae Serotype 1 Strains and in vitro effects of antimicrobials on toxin production and release. Microbiol. Immunol. 48: 965-969.

Eggert, U.S., Ruiz, N., Falcone, B.V., Branstrom, A.A., Goldman, R.C., Silhavy, T.J., and Kahne, D. 2001. Genetic basis for activity differences between vancomycin and glycolipid derivatives of vancomycin. Science 294: 361-364.

Ernst, R.K., Guina, T., and Miller, S.I. 2001. Salmonella typhimurium outer membrane remodeling: Role in resistance to host innate immunity. Microbes Infect. 3: 1327-1334.

Fiocca, R., Necchi, V., Sommi, P., Ricci, V., Telford, J., Cover,
T.L., and Solcia, E. 1999. Release of Helicobacter pylori vacuolating cytotoxin by both a specific secretion pathway and budding of outer membrane vesicles. Uptake of released toxin and vesicles by gastric epithelium. J. Pathol. 188: 220 226.

Fives-Taylor, P.M., Meyer, D.H., Mintz, K.P., and Brissette, C. 2000. Virulence factors of Actinobacillus actinomycetemcomitans. Periodontol. 20: 136-167.

Galdiero, M., Folgore, A., Molitierno, M., and Greco, R. 1999. Porins and lipopolysaccharide (LPS) from Salmonella typhimurium induce leucocyte transmigration through human endothelial cells in vitro. Clin. Exp. Immunol. 116: 453-461.

Gamazo, C. and Moriyon, I. 1987. Release of outer membrane fragments by exponentially growing Brucella melitensis cells. Infect. Immun. 55: 609-615.

Gankema, H., Wensink, J., Guinee, P.A., Jansen, W.H., and Witholt, B. 1980. Some characteristics of the outer membrane material released by growing enterotoxigenic Escherichia coli. Infect. Immun. 29: 704-713.

Garcia-del Portillo, F., Stein, M.A., and Finlay, B.B. 1997. Release of lipopolysaccharide from intracellular compartments containing Salmonella typhimurium to vesicles of the host epithelial cell. Infect. Immun. 65: 24-34.

Grenier, D. and Mayrand, D. 1987. Functional characterization of extracellular vesicles produced by Bacteroides gingivalis. Infect. Immun. 55: 111-117.

Heczko, U., Smith, V.C., Mark Meloche, R., Buchan, A.M., and Finlay, B.B. 2000. Characteristics of Helicobacter pylori attachment to human primary antral epithelial cells. Microbes Infect. 2: 1669-1676.

Hellman, J. and Warren, H.S. 2001. Outer membrane protein A (OmpA), peptidoglycan-associated lipoprotein (PAL), and murein lipoprotein (MLP) are released in experimental Gram-negative sepsis. J. Endotoxin Res. 7: 69-72.

Hellman, J., Zanzot, E.M., Loiselle, P.M., Amato, S.F., Black, K.M., Ge, Y., Kurnick, J.T., and Warren, H.S. 1997. Antiserum against Escherichia coli J5 contains antibodies reactive with outer membrane proteins of heterologous Gram-negative bacteria. J. Infect. Dis. 176: 1260-1268.

Hellman, J., Loiselle, P.M., Tehan, M.M., Allaire, J.E., Boyle, L.A., Kurnick, J.T., Andrews, D.M., Sik Kim, K., and Warren, H.S. 2000a. Outer membrane protein A, peptidoglycan-associated lipoprotein, and murein lipoprotein are released by Escherichia coli bacteria into serum. Infect. Immun. 68: 2566-2572.

Hellman, J., Loiselle, P.M., Zanzot, E.M., Allaire, J.E., Tehan, M.M., Boyle, L.A., Kurnick, J.T., and Warren, H.S. 2000b. Release of Gram-negative outer-membrane proteins into human serum and septic rat blood and their interactions with immunoglobulin in antiserum to Escherichia coli J5. J. Infect. Dis. 181: 1034-1043.

Henderson, I.R., Navarro-Garcia, F., Desvaux, M., Fernandez, R.C., and Ala'Aldeen, D. 2004. Type V protein secretion pathway: The autotransporter story. Microbiol. Mol. Biol. Rev. 68: 692-744.

Hoekstra, D., van der Laan, J.W., de Leij, L., and Witholt, B. 1976. Release of outer membrane fragments from normally growing Escherichia coli. Biochim. Biophys. Acta 455: 889899.

Horstman, A.L. and Kuehn, M.J. 2000. Enterotoxigenic Escherichia coli secretes active heat-labile enterotoxin via outer membrane vesicles. J. Biol. Chem. 275: 12489-12496.

- 2002. Bacterial surface association of heat-labile enterotoxin through lipopolysaccharide after secretion via the general secretory pathway. J. Biol. Chem. 26: 26.

Horstman, A.L., Bauman, S.J., and Kuehn, M.J. 2004. Lipopoly- 
saccharide 3-deoxy-D-manno-octulosonic acid (Kdo) core determines bacterial association of secreted toxins. J. Biol. Chem. 279: 8070-8075.

Ismail, S., Hampton, M.B., and Keenan, J.I. 2003. Helicobacter pylori outer membrane vesicles modulate proliferation and interleukin-8 production by gastric epithelial cells. Infect. Immun. 71: 5670-5675.

Kadurugamuwa, J.L. and Beveridge, T.J. 1995. Virulence factors are released from Pseudomonas aeruginosa in association with membrane vesicles during normal growth and exposure to gentamicin: A novel mechanism of enzyme secretion. $J$. Bacteriol. 177: 3998-4008.

- 1996. Bacteriolytic effect of membrane vesicles from Pseudomonas aeruginosa on other bacteria including pathogens: Conceptually new antibiotics. J. Bacteriol. 178: 27672774.

- 1997. Natural release of virulence factors in membrane vesicles by Pseudomonas aeruginosa and the effect of aminoglycoside antibiotics on their release. I. Antimicrob. Chemother. 40: 615-621.

. 1998. Delivery of the non-membrane-permeative antibiotic gentamicin into mammalian cells by using Shigella flexneri membrane vesicles. Antimicrob. Agents Chemother. 42: 1476-1483.

- 1999. Membrane vesicles derived from Pseudomonas aeruginosa and Shigella flexneri can be integrated into the surfaces of other Gram-negative bacteria. Microbiology 145: 2051-2060.

Kadurugamuwa, J.L., Mayer, A., Messner, P., Sara, M., Sleytr, U.B., and Beveridge, T.J. 1998. S-layered Aneurinibacillus and Bacillus spp. are susceptible to the lytic action of Pseudomonas aeruginosa membrane vesicles. I. Bacteriol. 180: 2306-2311.

Kamaguchi, A., Nakayama, K., Ichiyama, S., Nakamura, R., Watanabe, T., Ohta, M., Baba, H., and Ohyama, T. 2003a. Effect of Porphyromonas gingivalis vesicles on coaggregation of Staphylococcus aureus to oral microorganisms. Curr. Microbiol. 47: 485-491.

Kamaguchi, A., Ohyama, T., Sakai, E., Nakamura, R., Watanabe, T., Baba, H., and Nakayama, K. 2003b. Adhesins encoded by the gingipain genes of Porphyromonas gingivalis are responsible for co-aggregation with Prevotella intermedia. Microbiology 149: 1257-1264.

Kato, S., Kowashi, Y., and Demuth, D.R. 2002. Outer membrane-like vesicles secreted by Actinobacillus actinomycetemcomitans are enriched in leukotoxin. Microb. Pathog. 32: $1-13$.

Keenan, J.I. and Allardyce, R.A. 2000. Iron influences the expression of Helicobacter pylori outer membrane vesicle-associated virulence factors. Eur. I. Gastroenterol. Hepatol. 12: $1267-1273$.

Keenan, J., Day, T., Neal, S., Cook, B., Perez-Perez, G., Allardyce, R., and Bagshaw, P. 2000. A role for the bacterial outer membrane in the pathogenesis of Helicobacter pylori infection. FEMS Microbiol. Lett. 182: 259-264.

Kesty, N.C. and Kuehn, M.J. 2004. Incorporation of heterologous outer membrane and periplasmic proteins into Escherichia coli outer membrane vesicles. J. Biol. Chem. 279: 2069-2076.

Kesty, N.C., Mason, K.M., Reedy, M., Miller, S.E., and Kuehn, M.J. 2004. Enterotoxigenic Escherichia coli vesicles target toxin delivery into mammalian cells. EMBO J. 23: 4538-4549.

Khandelwal, P. and Banerjee-Bhatnagar, N. 2003. Insecticidal activity associated with the outer membrane vesicles of Xenorhabdus nematophilus. Appl. Environ. Microbiol. 69: 2032-2037.
Kobayashi, H., Uematsu, K., Hirayama, H., and Horikoshi, K. 2000. Novel toluene elimination system in a toluene-tolerant microorganism. J. Bacteriol. 182: 6451-6455.

Kolling, G.L. and Matthews, K.R. 1999. Export of virulence genes and Shiga toxin by membrane vesicles of Escherichia coli O157:H7. Appl. Environ. Microbiol. 65: 1843-1848.

Kondo, K., Takade, A., and Amako, K. 1993. Release of the outer membrane vesicles from Vibrio cholerae and Vibrio parahaemolyticus. Microbiol. Immunol. 37: 149-152.

Lai, C.H., Listgarten, M.A., and Hammond, B.F. 1981. Comparative ultrastructure of leukotoxic and non-leukotoxic strains of Actinobacillus actinomycetemcomitans. I. Periodontal Res. 16: 379-389.

Lerouge, I. and Vanderleyden, J. 2002. O-Antigen structural variation: Mechanisms and possible roles in animal/plantmicrobe interactions. FEMS Microbiol. Rev. 26: 17-47.

Li, Z., Clarke, A., and Beveridge, T.J. 1996. A major autolysin of Pseudomonas aeruginosa: Subcellular distribution, potential role in cell growth and division and secretion in surface membrane vesicles. J. Bacteriol. 178: 2479-2488.

- 1998. Gram-negative bacteria produce membrane vesicles which are capable of killing other bacteria. J. Bacteriol. 180: 5478-5483.

Loeb, M.R. 1974. Bacteriophage T4-mediated release of envelope components from Escherichia coli. J. Virol. 13: 631-641.

Loeb, M.R. and Kilner, J. 1978. Release of a special fraction of the outer membrane from both growing and phage T4-infected Escherichia coli B. Biochim. Biophys. Acta 514: 117127.

Logan, S.M. and Trust, T.J. 1982. Outer membrane characteristics of Campylobacter jejuni. Infect. Immun. 38: 898-906.

Mayrand, D. and Grenier, D. 1989. Biological activities of outer membrane vesicles. Can. J. Microbiol. 35: 607-613.

Mayrand, D. and Holt, S.C. 1988. Biology of asaccharolytic blackpigmented Bacteroides species. Microbiol. Rev. 52: 134-152.

McBroom, A. and Kuehn, M.J. 2005. Outer membrane vesicles. In EcoSal-Escherichia coli and Salmonella: Cellular and molecular biology (ed. R. Curtiss III), Chapter 2.2.4 [Online]. ASM Press, Washington, DC.

Meadow, P.M., Wells, P.L., Salkinoja-Salonen, M., and Nurmiaho, E.L. 1978. The effect of lipopolysaccharide composition on the ultrastructure of Pseudomonas aeruginosa. J. Gen. Microbiol. 105: 23-28.

Meyer, D.H. and Fives-Taylor, P.M. 1994. Characteristics of adherence of Actinobacillus actinomycetemcomitans to epithelial cells. Infect. Immun. 62: 928-935.

Miller, V.L. and Falkow, S. 1988. Evidence for two genetic loci in Yersinia enterocolitica that can promote invasion of epithelial cells. Infect. Immun. 56: 1242-1248.

Mug-Opstelten, D. and Witholt, B. 1978. Preferential release of new outer membrane fragments by exponentially growing Escherichia coli. Biochim. Biophys. Acta 508: 287-295.

Namork, E. and Brandtzaeg, P. 2002. Fatal meningococcal septicaemia with 'blebbing' meningococcus. Lancet 360: 1741.

Negrete-Abascal, E., Garcia, R.M., Reyes, M.E., Godinez, D., and de la Garza, M. 2000. Membrane vesicles released by Actinobacillus pleuropneumoniae contain proteases and Apx toxins. FEMS Microbiol. Lett. 191: 109-113.

Nguyen, T.T., Saxena, A., and Beveridge, T.J. 2003. Effect of surface lipopolysaccharide on the nature of membrane vesicles liberated from the Gram-negative bacterium Pseudomonas aeruginosa. J. Electron Microsc. (Tokyo) 52: 465469.

Nowotny, A., Behling, U.H., Hammond, B., Lai, C.H., Listgarten, M., Pham, P.H., and Sanavi, F. 1982. Release of toxic microvesicles by Actinobacillus actinomycetemcomitans. 
Infect. Immun. 37: 151-154.

Ohta, H., Kato, K., Kokeguchi, S., Hara, H., Fukui, K., and Murayama, Y. 1991. Nuclease-sensitive binding of an Actinobacillus actinomycetemcomitans leukotoxin to the bacterial cell surface. Infect. Immun. 59: 4599-4605.

Ohta, H., Hara, H., Fukui, K., Kurihara, H., Murayama, Y., and Kato, K. 1993. Association of Actinobacillus actinomycetemcomitans leukotoxin with nucleic acids on the bacterial cell surface. Infect. Immun. 61: 4878-4884.

Patrick, S., McKenna, J.P., O'Hagan, S., and Dermott, E. 1996. A comparison of the haemagglutinating and enzymic activities of Bacteroides fragilis whole cells and outer membrane vesicles. Microb. Pathog. 20: 191-202.

Pettit, R.K. and Judd, R.C. 1992. The interaction of naturally elaborated blebs from serum-susceptible and serum-resistant strains of Neisseria gonorrhoeae with normal human serum. Mol. Microbiol. 6: 729-734.

Pier, G.B. 2000. Peptides, Pseudomonas aeruginosa, polysaccharides and lipopolysaccharides-Players in the predicament of cystic fibrosis patients. Trends Microbiol. 8: 247250; discussion 250-241.

Qi, M., Miyakawa, H., and Kuramitsu, H.K. 2003. Porphyromonas gingivalis induces murine macrophage foam cell formation. Microb. Pathog. 35: 259-267.

Renelli, M., Matias, V., Lo, R.Y., and Beveridge, T.J. 2004. DNAcontaining membrane vesicles of Pseudomonas aeruginosa PAO1 and their genetic transformation potential. Microbiology 150: 2161-2169.

Rolhion, N., Barnich, N., Claret, L., and Darfeuille-Michaud, A. 2005. Strong decrease in invasive ability and outer membrane vesicle release in Crohn's disease-associated adherentinvasive Escherichia coli strain LF82 with the yfgL gene deleted. J. Bacteriol. 187: 2286-2296.

Rosen, G., Naor, R., Rahamim, E., Yishai, R., and Sela, M.N. 1995. Proteases of Treponema denticola outer sheath and extracellular vesicles. Infect. Immun. 63: 3973-3979.

Sabra, W., Lunsdorf, H., and Zeng, A.P. 2003. Alterations in the formation of lipopolysaccharide and membrane vesicles on the surface of Pseudomonas aeruginosa PAO1 under oxygen stress conditions. Microbiology 149: 2789-2795.

Saunders, N.B., Shoemaker, D.R., Brandt, B.L., Moran, E.E., Larsen, T., and Zollinger, W.D. 1999. Immunogenicity of intranasally administered meningococcal native outer membrane vesicles in mice. Infect. Immun. 67: 113-119.

Schnaitman, C.A. and Klena, J.D. 1993. Genetics of lipopolysaccharide biosynthesis in enteric bacteria. Microbiol. Rev 57: 655-682.

Sharma, A., Novak, E.K., Sojar, H.T., Swank, R.T., Kuramitsu, H.K., and Genco, R.J. 2000. Porphyromonas gingivalis platelet aggregation activity: Outer membrane vesicles are potent activators of murine platelets. Oral Microbiol. Immunol. 15: 393-396.

Shoberg, R.J. and Thomas, D.D. 1993. Specific adherence of Borrelia burgdorferi extracellular vesicles to human endothelial cells in culture. Infect. Immun. 61: 3892-3900.

Smit, J., Kamio, Y., and Nikaido, H. 1975. Outer membrane of Salmonella typhimurium: Chemical analysis and freezefracture studies with lipopolysaccharide mutants. I. Bacteriol. 124: 942-958.

Sommi, P., Ricci, V., Fiocca, R., Necchi, V., Romano, M., Telford, J.L., Solcia, E., and Ventura, U. 1998. Persistence of Helicobacter pylori VacA toxin and vacuolating potential in cultured gastric epithelial cells. Am. J. Physiol. 275: G681-G688.

Srisatjaluk, R., Doyle, R.J., and Justus, D.E. 1999. Outer membrane vesicles of Porphyromonas gingivalis inhibit IFN- $\gamma$ mediated MHC class II expression by human vascular endo- thelial cells. Microb. Pathog. 27: 81-91.

Srisatjaluk, R., Kotwal, G.J., Hunt, L.A., and Justus, D.E. 2002. Modulation of $\gamma$ interferon-induced major histocompatibility complex class II gene expression by Porphyromonas gingivalis membrane vesicles. Infect. Immun. 70: 1185-1192.

Stathopoulos, C., Hendrixson, D.R., Thanassi, D.G., Hultgren, S.J., St Geme III, J.W., and Curtiss III, R. 2000. Secretion of virulence determinants by the general secretory pathway in Gram-negative pathogens: An evolving story. Microbes Infect. 2: 1061-1072.

Stephens, D.S., Edwards, K.M., Morris, F., and McGee, Z.A. 1982. Pili and outer membrane appendages on Neisseria meningitidis in the cerebrospinal fluid of an infant. J. Infect. Dis. 146: 568.

Stirling, P. and Richmond, S.J. 1980. Production of outer membrane blebs during Chlamydial replication. FEMS Microbiol. Lett. 9: 103-105.

Tauschek, M., Gorrell, R.J., Strugnell, R.A., and Robins-Browne, R.M. 2002. Identification of a protein secretory pathway for the secretion of heat-labile enterotoxin by an enterotoxigenic strain of Escherichia coli. Proc. Natl. Acad. Sci. 99: 7066-7071.

Vesy, C.J., Kitchens, R.L., Wolfbauer, G., Albers, J.J., and Munford, R.S. 2000. Lipopolysaccharide-binding protein and phospholipid transfer protein release lipopolysaccharides from Gram-negative bacterial membranes. Infect. Immun. 68: $2410-2417$.

Wai, S.N., Takade, A., and Amako, K. 1995. The release of outer membrane vesicles from the strains of enterotoxigenic Escherichia coli. Microbiol. Immunol. 39: 451-456.

Wai, S.N., Lindmark, B., Soderblom, T., Takade, A., Westermark, M., Oscarsson, J., Jass, J., Richter-Dahlfors, A., Mizunoe, Y., and Uhlin, B.E. 2003. Vesicle-mediated export and assembly of pore-forming oligomers of the enterobacterial ClyA cytotoxin. Cell 115: 25-35.

Wensink, J., Gankema, H., Jansen, W.H., Guinee, P.A., and Witholt, B. 1978. Isolation of the membranes of an enterotoxigenic strain of Escherichia coli and distribution of enterotoxin activity in different subcellular fractions. Biochim. Biophys. Acta 514: 128-136.

Whitchurch, C.B., Tolker-Nielsen, T., Ragas, P.C., and Mattick, J.S. 2002. Extracellular DNA required for bacterial biofilm formation. Science 295: 1487.

Whitmire, W.M. and Garon, C.F. 1993. Specific and nonspecific responses of murine $\mathrm{B}$ cells to membrane blebs of Borrelia burgdorferi. Infect. Immun. 61: 1460-1467.

Williams, G.D. and Holt, S.C. 1985. Characteristics of the outer membrane of selected oral Bacteroides species. Can. J. Microbiol. 31: 238-250.

Yaganza, E.S., Rioux, D., Simard, M., Arul, J., and Tweddell, R.J. 2004. Ultrastructural alterations of Erwinia carotovora subsp. atroseptica caused by treatment with aluminum chloride and sodium metabisulfite. Appl. Environ. Microbiol. 70: 6800-6808.

Yaron, S., Kolling, G.L., Simon, L., and Matthews, K.R. 2000. Vesicle-mediated transfer of virulence genes from Escherichia coli O157:H7 to other enteric bacteria. Appl. Environ. Microbiol. 66: 4414-4420.

Yokoyama, K., Horii, T., Yamashino, T., Hashikawa, S., Barua, S., Hasegawa, T., Watanabe, H., and Ohta, M. 2000. Production of shiga toxin by Escherichia coli measured with reference to the membrane vesicle-associated toxins. FEMS Microbiol. Lett. 192: 139-144.

Zhou, L., Srisatjaluk, R., Justus, D.E., and Doyle, R.J. 1998. On the origin of membrane vesicles in Gram-negative bacteria. FEMS Microbiol. Lett. 163: 223-228. 


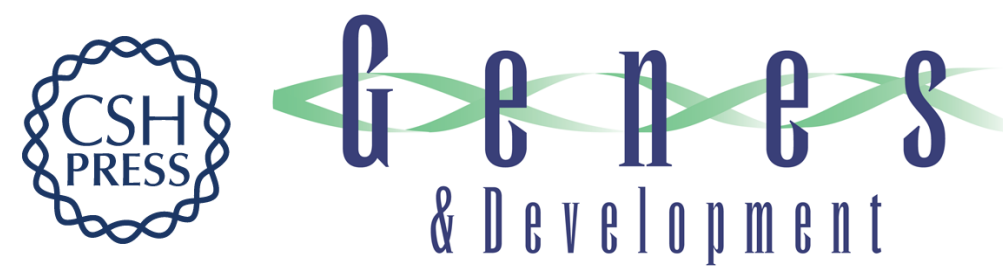

\section{Bacterial outer membrane vesicles and the host-pathogen interaction}

Meta J. Kuehn and Nicole C. Kesty

Genes Dev. 2005, 19:

Access the most recent version at doi:10.1101/gad.1299905

References This article cites 111 articles, 55 of which can be accessed free at: http://genesdev.cshlp.org/content/19/22/2645.full.html\#ref-list-1

License

Email Alerting Receive free email alerts when new articles cite this article - sign up in the box at the top Service right corner of the article or click here.

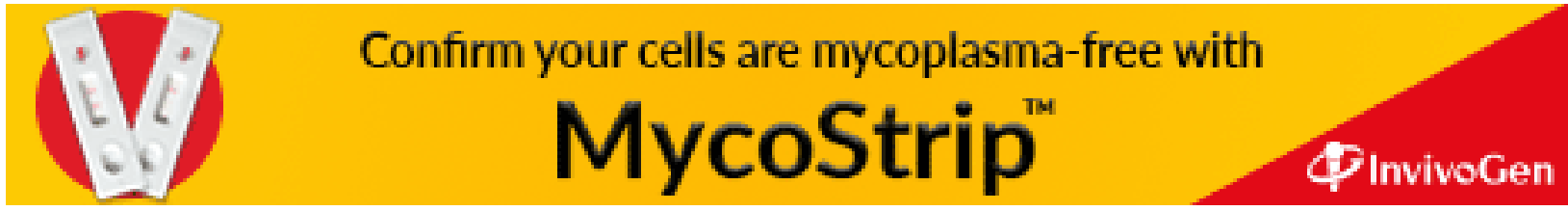

